\title{
We Are All In This Together: Supporting Hearts and Minds During Unprecedented Times
}

\author{
Marie-Anne Hudson and Lori Huston
}

\begin{abstract}
Marie-Anne Hudson (she/her) has a master's degree in early childhood education from the University of British Columbia. She is a program and policy development specialist with the Early Learning and Child Development Division, Newfoundland and Labrador Department of Education and brings 30 years of education and experience to the field of early childhood education. She is a strong advocate for social-emotional learning and mental health, personally and professionally, as a foundation for knowing and doing, and she is passionate about leadership and empowerment. E-mail: mahudson@nf.sympatico.ca
\end{abstract}

Lori Huston (she/her) is of mixed descent: Métis, Scottish, and British. She currently works as an Indigenous curriculum specialist in the ECE department of Humber College Institute of Technology \& Advanced Learning. She is a doctoral student in education curriculum and pedagogy in the Faculty of Education, University of British Columbia. Lori's cumulative experiences in research and graduate work have focused on Indigenous ECE leadership, which highlights Indigenous pedagogies connected to reconciliation, place, and land-based teachings. Lori founded a mentorship program called Rising Indigenous Voices in Early Learning. Email: le.huston@outlook.com

This article discusses the potential that traumainformed pedagogy and social-emotional learning practices hold for supporting educators during the COVID-19 pandemic and beyond. The authors bring a critical lens to considering these approaches, noting some limitations and provisos in their use. We advocate for dialogue, mentorship, and professional learning in using them not only to support educators but to authentically include diverse ways of knowing, doing, and being in early childhood environments.

Key words: early childhood education; socialemotional learning; trauma-informed
Throughout the past 19 months of the COVID-19 pandemic, the words "We are all in this together" have resounded across Canada and around the world. This phrase can be interpreted many ways. In both global and local contexts, it suggests that each of us has to do our part to care for and protect one another to reduce the spread of the virus. However, the pandemic is affecting individuals and communities in very different ways (Dawe, 2021; Warren \& Bordoloi, 2020) and has created great divides socially, politically, economically, and intellectually (Bascaramurty, 2020; Statistics Canada, 2020, Yang et al., 2020; Yong, 2021). COVID-19 has shone a bright lightnot only on social injustices and inequalities, especially for vulnerable and marginalized people, but also on diverse and often dichotomous viewpoints within the early years field. If we are truly "all in this together," how do we in the early years field support each other's hearts and minds while also supporting diversity and inclusion?

We, Marie-Anne Hudson and Lori Huston, in our separate roles as advocates for early childhood education (ECE) and early childhood educators (ECEs), have been listening throughout the pandemic to the voices and fears of the ECE community, locally through our ECE connections and nationally through the media. Narratives have emerged in the media about "essential" and "nonessential" workers. As advocates with long histories of working in the early years field, we recognize ECEs as unquestionably essential to the fabric of Canadian society. We respect their knowledge and practice in the care, protection, and education of children. And we are passionate about supporting them in navigating the changes COVID-19 has brought to our field.

As advocates, we believe that if we going to examine the pandemic's effects on the early years field at this moment through a magnifying glass, we would be remiss if we did not also take out binoculars to view its fartherreaching effects and long-term implications for early childhood policy and practice. On one hand, the pandemic 
is providing an impetus for growth and change, as in the federal government's April 2021 announcement of a plan for universal child care (Government of Canada, 2021a). On the other hand, COVID-19 has caused stress, anxiety, and trauma-individual and collective trauma (Sherwood et al., 2021), both in society at large and in early childhood environments.

The well-being of many children and families has diminished in social isolation (Warren \& Bordoloi, 2020). Many are struggling to access education and basic life necessities. ECEs' well-being has diminished too. Many ECEs we have talked to are afraid about children's and their own exposure to a virus that has taken many lives and strained both the health care system and the economy. Some educators wonder how to balance the care and education of young children with protecting themselves and their loved ones from viruses, now and in the future. In a recent interview with Lori, Jerephine Williams Sakakeep from North Caribou Lake First Nation in Ontario said that "coming to work and making sure everyone is safe, and following new pandemic community protocols, which change from time to time, has been [her] biggest challenge" (AECEO, 2021, p. 11). Throughout this pandemic, ECEs have been forerunners of providing universal care and precautions while following strict safety protocols, but many report feeling ill-equipped, as Canadian society "reopens," to work with the stress and trauma COVID-19 continues to create.

In this article, we consider whether trauma-informed pedagogy (TIP) and social-emotional learning (SEL) practices hold potential to create pathways toward supporting the hearts and minds of educators as well as young children during the COVID-19 pandemic and beyond. We begin by locating ourselves and our advocacy work in the field. Then, drawing from a review of TIP and SEL literature ${ }^{1}$ that we conducted for an earlier purpose and from our advocacy work, we define TIP and SEL and explore the possibilities these approaches ignite in early childhood environments. This discussion highlights intersections and overlap between the two concepts, including their affinity with Indigenous ways of knowing and being, and also notes some limitations and provisos in working with TIP and SEL approaches. Our focus is exploring the capacity of these strategies to support ECEs' hearts and minds in their work with young children and to respect diverse ways of knowing and being. Following some suggestions for future research, practice, and policy development related to these approaches, we draw a few conclusions in support of storying an early years field in which we are truly are "all in this together."

\section{Our journeys of support and advocacy}

We, Marie-Anne and Lori, have long-standing backgrounds supporting ECEs in engaging authentically with children and families in ways that support wholistic development. We are acutely aware of the impacts of trauma and adverse childhood experiences on the lives of children and families, and we share an understanding of the role that ECEs play in mediating children's social-emotional learning-and of the secondary trauma they may experience when caring for and supporting children and families who have experienced trauma (Sherwood et al., 2021). Marie-Anne has worked in ECE in various capacities for over 30 years and currently develops programs and policies for the early childhood sector on Canada's east coast. She recently completed a graduate degree in ECE through the University of British Columbia, focusing on social-emotional learning for children and educators. Marie-Anne has a keen interest in narrative pedagogy and examines early childhood frameworks and practices from a critical, feminist perspective informed by Karen Barad's (2014) ideas about diffraction. Lori's background includes 12 years of coordinating an Indigenous ECE postsecondary diploma program with Oshki-Wenjack in Thunder Bay, Ontario. For more than 25 years, Lori provided trauma-informed education embedded in Indigenous teachings-working toward decolonizing education, without naming it or knowing her Indigenous ancestry, alongside Elders, Indigenous families, and educators. Due in part to Canada's colonial fabric, Lori learned only recently of her Métis ancestry. She is now a citizen of the Métis Nation in Ontario. Her research, practices, and 
projects focus on leadership in Indigenous ECE and highlight Indigenous pedagogies connected to reconciliation, place, and land-based teachings.

Both of us are on journeys of support and advocacy in the ECE field, Lori more directly with educators and Marie-Anne at the macro level, creating and revising policies in an ever-changing, ever-expanding field. During this unprecedented time in our global history with the pandemic and soaring social injustices, ECEs across Canada have expressed to both of us feelings of fear, stress, and anxiety. While we were aware prior to COVID-19 that early learning and child care in Canada was in a fragile state-due in large part to a lack of a national framework or universal access-we became increasingly concerned about how those directly working and interacting with children were managing during the pandemic. These concerns led us to think critically about the need for trauma-informed pedagogies in early childhood and the availability of professional development and resources for educators in supporting both children's well-being and their own. Lori's work with trauma-informed practices (TIPs) and Marie-Anne's research into social-emotional learning (SEL) led us to conclude that these two approaches, particularly in combination, hold potential to support hearts and minds-of children, certainly, but also of educators - provided that the approaches themselves are supported with professional learning, mentorship, and dialogue. We suggest that when TIPs and SEL are interconnected, opportunities arise for social growth and transformation.

We do, however, bring a critical lens to considering these approaches. At the heart of this article is our deep desire to create space to story ECEs' diverse voices as they navigate the challenges and opportunities created by the COVID-19 pandemic. A central path in our own ways of knowing, being, and doing is the concept of community. Therefore, we advocate for grounding these approaches in community, and we suggest that TIP and SEL programs must consider both developmental knowledge and Indigenous knowledges of inclusive, diverse, and wholistic ways to support and connect the heart and mind. We argue that evidence-based scripted or prepackaged programs may have positive outcomes for some children and educators, but they will not be appropriate for all. TIP and SEL practices must consider the local context, local knowledges, individual differences, communities' vision for their own children, and cultural identity, among other factors, some of which we touch on in this article.

Next, we define the terms TIP and SEL, as we use them, and then explain why we think they are important for early childhood educators, particularly during these unprecedented times.

\section{What are trauma-informed pedagogy and social-emotional learning?}

The concept of trauma-informed practice (TIP) originated in the health care field in the 1970s when medical professionals identified widespread posttraumatic stress disorder (PTSD) among returning Vietnam War veterans (Ohio Leadership Advisory Council, n.d.). The concept was brought to education after a large-scale study by Felliti and colleagues (1998) of the impact of adverse childhood experiences (ACEs, i.e., trauma) on children's development. The two-year study of 17,000 adults "provided evidence about the significant prevalence of adverse experiences in the lives of children ... and the critical need to invest in interventions to prevent and interrupt the long-term consequences of ACEs as early as possible" (Nicholson et al., 2018, p. x).

Trauma-informed practices (TIPs) integrate "various strengths-based and relationship-based approaches and theories that all aim to do no further harm" (Nicholson et al., 2018, p. x) when someone has been traumatized. For example, in the context of childhood trauma, the specific goal of TIP is to not retraumatize the child but rather "to guide [the] child toward health and healing" (p. x). We want to emphasize that TIPs are not intended to treat trauma. Instead, these practices prioritize principles of "safety; trustworthiness and transparency; peer support; collaboration and mutuality; empowerment, voice and choice" (SAMHSA, 2014, p. 10). We suggest that these 
principles must be embedded within a culturally responsive framework that pays attention to social-emotional learning (SEL).

Like TIP, SEL is not a theory; rather, it is a process "through which children and adults understand and manage emotions, set and achieve positive goals, feel and show empathy for others, establish and maintain positive relationships, and make responsible decisions" (Collaborative for Academic Social Emotional Learning [CASEL], 2021, para. 1). In our view, there is a strong connection between SEL and Indigenous perspectives that are rooted in relationships with the natural world and other people (e.g., the self, the family, ancestors, clan, community, nation, and other nations). In our experience, thoughtful weaving of relation-based Indigenous knowledge into early childhood curricula, done in partnership with Indigenous people, strengthens pedagogical processes experienced by both Indigenous and non-Indigenous learners, because wholistic learning engages all four domains of knowledge-spiritual, cognitive, emotional, physical— to nourish wholistic development. ${ }^{2}$ Below we explore in more detail how these approaches can support hearts and minds in the early years field.

\section{How can TIP and SEL support early childhood educators?}

We all experience trauma in our lives. Adverse experiences are part of the human experience. But the injustices and realities of our current times-racism, rampant violence, the devastating effects of climate change, and now, a deadly pandemic - are making trauma a more frequent, more complex experience in all arenas of Canadian life, including early childhood environments. In responding to these experiences, trauma-informed SEL programs can provide a useful framework-when applied in culturally responsive ways.

Trauma is by no means experienced equally. For example, all Indigenous people in Canada have inherited trauma connected to a loss of culture and place due to many generations being forcibly removed from their families, communities, and homelands (Sam, 2019, p. 9) in acts of attempted assimilation that amounted to genocide (Truth and Reconciliation Commission of Canada, 2015). This inherited trauma lives alongside the trauma of experiencing racism and its effects on a daily basis (Clark, 2016). These effects include being disproportionately impacted by the COVID-19 pandemic due to "factors such as ... lack of access to effective monitoring and early-warning systems, and adequate health and social services" (United Nations, n.d.). It is clear that the pandemic has been experienced unequally. It is also clear that it affects us all, either directly in the form of illness or isolation or indirectly through constant media alerts and reminders. We must remember, however, as we have heard many times throughout the pandemic (e.g., Dawe, 2021), that while we may all be navigating the same storm, we are in different boats.

As advocates in early childhood education, we are keenly aware that educators too have been affected differently by COVID. While K-12 schools, colleges, and universities switched to online teaching and learning early in the pandemic, early years environments were deemed to be essential services, and ECEs were immediately faced with managing their own fears and anxieties as they looked for ways to support children and families. Questions emerged from ECEs in some provinces and territories as to why it was okay for child care centres to reopen when it was deemed unsafe for schools and universities to open their doors. During this time, Lori took on the critical role of community organizing to amplify the voices of educators, families, operators, and social movement allies in responding to policy decisions in the wake of COVID-19. This work was done in communities of practice with the Association of Early Childhood Educators Ontario (AECEO) and within the Rising Indigenous Voices mentorship program. In Ontario, while home child care remained open, licensed child care centres closed and the early childhood workforce was laid off in large numbers; families were left to take on dual roles in working from home while caring for and educating their children. The Ontario government's lack of communication, clarity, and support for the sector left operators, educators, and families isolated and anxious as they struggled to find 
information and a sense of community. The situation was different in Newfoundland and Labrador. Following an initial two-week lockdown, the provincial government provided funding and other supports and resources to ensure that regulated child care centres and family homes that had essential workers enrolled were supported in being open; no staff were laid off if services availed themselves of the funding. A daily public news release provided updates, and the Department of Education also provided regular updates through e-mails and FAQ memos. In each territory and province, the government response was different (Childcare Resource and Research Unit, 2020, 2021; Friendly, Forer, \& Vickerson, 2020), which resulted in markedly different experiences of the pandemic in different parts of the country.

So, while the pandemic's effects have been unequal, this highly contagious virus has forever changed the ways of knowing, being, and doing in our field. We, Marie-Anne and Lori, view TIP and SEL in much the same way. Just as it is wise to assume that anyone we encounter could be carrying the virus and therefore we should practice precautions in all of our interactions with others, we suggest it is likely that everyone in the early childhood environment has experienced trauma; therefore, implementing high-quality universal wellness promotion programs such as TIP and SEL supports the social and emotional well-being of all. While there is no "one-size fits all" approach and programs must be applied in culturally responsive ways, research documents positive short- and long-term outcomes in their implementation (e.g., Bond \& Hauf, 2004; Durlack et al., 2011; Jones \& Doolittle, 2017). Trauma will be a salient consideration as children and educators return to early childhood environments in the coming days, weeks, months, and years post-pandemic. Therefore, we as advocates would like to see the kinds of TIP and SEL strategies now being used to support children adapted to support educators, as we discuss next.

\section{Adapting strategies for supporting children to support educators}

Many TIP and SEL approaches are outlined in the literature to support children in developing SEL competencies, including, for example, SEL in support of school readiness (Mashburn \& Pianta, 2006), equity-seeking frameworks (Jagers et al., 2019), relational approaches (Whitington \& McInnes, 2017), the "power threat meaning" framework (Harper \& Cromby, 2020; Read \& Harper, 2020), and many others (e.g., Dorado et al., 2016; Greenberg et al., 2003; Hatton-Bowers et al., 2020; Jennings \& Greenberg, 2009). Many of these approaches can inform programs for educators or be adapted to support educators.

Some SEL approaches used with children have already proven beneficial for adults. For example, Razza and colleagues (2019) examined an eight-week yoga program for preschoolers living in communities coping with extreme trauma. Not only did the program provide social-emotional benefits for children, but the researchers also noted benefits for the staff, who had a high prevalence of PTSD themselves. The participants in another study also acknowledged the benefits of mindfulness training, specifically for improving the quality of interpersonal and intrapersonal relationships (Hatton-Bowers et al., 2020). The study participants noted that mindfulness involves intentionality, self-awareness, being present, taking a pause, and considering a response. Programs that teach and support mindfulness could be beneficial for ECEs who are dealing with the stresses and risks of the workplace during a pandemic.

As we noted above, there is a strong ontological connection between SEL approaches and Indigenous pedagogies, and some of the fruitful examples in our literature review were derived from the latter. For example, Hodson et al. (2020) heard from more than 30 Indigenous educators who shared their passion for changing their current outdoor learning environments to include traditional knowledges and practices that support TIP. These educators had visions of including Elders in programming, incorporating cultural teachings on the land, and connecting children to how the land supports their identity and interconnectedness with all beings (Cajete, 2000). The educators found 
that a heightened awareness of identity resulted in unique, community-driven forms of land-based learning. For example, one community of Indigenous educators hosted a three-day hunting camp for women and girls (participants ranged in age from 3 to 57) to shoot and clean a moose together (Hodson et al., 2020, p. 11).

Grief is another part of the COVID-19 trauma experience-more than 28,000 Canadians have died with the virus so far (Government of Canada, 2021b). Both of us, Marie-Anne and Lori, experienced profound personal losses during the pandemic. Marie-Anne's mother and Lori's father both passed away. We know firsthand the pain of navigating COVID-19 protocols in relation to funeral and burial services, and of grieving those losses in isolation without the supportive presence of our communities and extended families. We know that many educators, children, and families experienced similar losses and grief. We suggest that ECEs are uniquely positioned to support children, families, colleagues, and themselves during grief and other stressful times through their knowledge and experiences with tools and strategies based on their everyday practices. For example, while a vast array of commercial resources such as children's books that address emotions are available, narrative pedagogy or storytelling is a useful alternative strategy that can be supportive and culturally sensitive. Another way to support educators (or for educators to provide mutual support) is through social activities and hands-on projects like growing food or creating art that offer opportunities for self-expression or for connecting with others, including the land. These activities could be made available in the context of a community of practice and/or in conjunction with professional learning about SEL and TIP.

Any SEL or TIP approaches developed or adapted to support educators need to be designed flexibly, because ECEs are diverse and the ways in which they respond to change or to trauma are diverse. For example, some educators are very comfortable with technology and connecting in the digital world while others are not. This diversity reinforces the idea that a one-size-fits-all program is unlikely to be appropriate and that multimodal understandings and practice are required.

\section{Implications for research, practice, and policy in the early years field}

SEL and TIP approaches in early childhood environments have only begun to emerge in the past decade (Oberle et al., 2016). Given a rapidly changing global landscape and ever-increasing stresses, traumas, and challenges in our society, we expect that research in these areas will develop exponentially in the coming months and years. Yet, how this research will look as we forge ahead in living with COVID-19 amid the many social injustices the pandemic has brought to light remains unknown.

Record-Lemon and Buchanan (2017), motivated by an influx of immigrants from war-torn countries, conducted an extensive (pre-COVID) literature review of TIPs in schools. ${ }^{3}$ They highlight a scarcity of research into TIP in Canada, which they note "is in stark contrast to the significant number of studies being conducted in the United States or overseas" (p. 301). Clearly this is a research gap that needs to be filled to inform our field about the usefulness of TIPS in specific Canadian contexts. Nicholson et al. (2018) describe a number of TIP approaches studied in early childhood contexts in the US. One they mention that would appear to be particularly appropriate for research with educators is somatization-body aches and pains that result from traumatic stress (Gray, 2007). Another promising area for research is what Oberle and Schonert-Reichl (2016) call stress contagion; they found a connection between educator burnout and stress levels of their young learners. Further studies in this area could contribute to promoting the well-being of both children and educators.

We sincerely hope that research in these practice areas expands to include educators as well as children. We also hope to see Indigenous ways of knowing included in research about SEL and TIP because we feel these two approaches align with Indigenous perspectives on the child's wholistic well-being, the centrality of family and community, 
and the land as a teacher. And, as the government of Canada moves forward with a national early learning and child care plan that is promised to be a community-based system of quality care (Government of Canada, 2021a), we will continue our advocacy work to remind the policy designers that "universal" is not to be interpreted as "one size fits all" but rather the plan must meet the needs of diverse communities so that high-quality, affordable, inclusive early learning and child care is provided no matter where one lives in Canada. To build such a system, it is essential that ECEs are empowered to engage in the process. In doing so, they will support both the children of today and the children of the future.

\section{Navigating new ways of knowing and doing}

COVID-19 has changed the ways of knowing and doing for ECEs at the most basic level. Keeping six feet apart is counterintuitive for ECEs, who use interactive and hands-on approaches to care and learning. But necessity leads to discovery, and many ECEs discovered that it's easier to keep children six feet apart outdoors. Further, COVID has prompted at least one study on the benefits of outdoor play (Lawson Foundation, 2020). Perhaps this research might lead provincial curriculum developers to consider the value of land-based teaching and learning and the social, emotional, cognitive, and spiritual benefits for children and educators. It presents an opportunity for all provinces and territories to include outdoor-based programs inclusive of Indigenous pedagogies in policy and curriculum.

As we engage new ways of knowing and doing to build safe, healthy relationships with the children in our care and with our colleagues, we must keep in mind that we don't have to work in isolation. Let's ensure that we continue to support each other with a wholistic perspective that values cognitive knowledge, self-awareness, emotional growth, social growth, and spiritual development equally.

COVID-19 is a traumatic event that has affected each and every one of us. In that sense, we are literally "all in it together," but in differing ways. Moving forward into an unknown future, the principles of TIP outlined by SAMHSA (2014) would serve our field well—safety, trustworthiness, transparency, peer support, collaboration, mutuality, choice, voice, and empowerment. For us as advocates for ECEs and the early years field, empowerment has been a tough one throughout this pandemic. How is empowerment possible when we are all powerless over a virus and when so many in our field have been held captive-isolated-for 19 months? But as the country "reopens," the pandemic is offering the early years field an opportunity to change the narrative of ECE and ECEs. There can no longer be any doubt in the public mind that ECE is essential, not only from a social or economic perspective in ensuring that Canadian society can function, but from a social-emotional perspective that honours ECEs' strength and resiliency in navigating the unprecedented and the unknown. While everyone's pathway forward will be different, we can through dialogue, advocacy, and professional learning support one another's hearts and minds. If, as a field, we do this, we can then say with authenticity that we are truly "in this together."

\footnotetext{
${ }^{1}$ Our review focused on the Canadian context, in part because we live and work in Canada and because ECE settings in this country are a patchwork system of private and nonprofit, regulated and unregulated, family and commercially based arrangements which, at the time of this writing, are not supported by federal policies or frameworks (Friendly, Ballantyne, \& Anderson, 2020). As advocates, we would like to see TIP and SEL approaches inform the development of the universal child care plan that the federal government promised in the 2021 budget speech (Government of Canada, 2021a).

${ }^{2}$ This example of a decolonizing approach to the SEL curriculum highlights the principle of doing no further harm.

${ }^{3}$ We anticipate that research in TIP and SEL practices conducted before the pandemic will guide policy planners and curriculum developers toward supporting current and ongoing advancements in ECE.
} 


\section{References}

Association of Early Childhood Educators Ontario (AECEO) Guiding Committee on Truth and Reconciliation. (2021). Sharing the experiences of Indigenous educators and communities during COVID-19. eceLINK, Spring, 8-12.

Barad, K. (2014). Diffracting diffraction: Cutting together-apart. Parallax, 20(3), 168-187. https://doi.org/10.1080/13534645.2014.9276 $\underline{23}$

Bascaramurty, D. (2020, March 17). How the pandemic is highlighting Canada's class divide. The Globe and Mail. https://www. theglobeandmail.com/canada/article-how-the-pandemic-is-highlighting-canadas-class-divide/

Bond, L. A., \& Hauf, A. M. C. (2004). Taking stock and putting stock in primary prevention: Characteristics of effective programs. The Journal of Primary Prevention, 24(3), 199-221. https://doi.org/10.1023/B:JOPP.0000018051.90165.65

Cajete, G. (2000). Native science: Natural laws of interdependence. Clear Light.

Childcare Resource and Research Unit. (2020, November 18). Re-opening child care centres during COVID-19-Provincial/territorial guidelines for minimizing risk: Staff:child ratios, groupings and group sizes, physical space and social distancing. https:// childcarecanada.org/

Childcare Resource and Research Unit. (2021). Childcare and COVID-19 in Canada. https://childcarecanada.org/resources/issue-files/ child-care-and-covid-19-canada

Clark, N. (2016). Shock and awe: Trauma as the new colonial frontier. Humanities, 5(14), 1-16. https://doi.org/10.3390/h5010014

Collaborative for Academic, Social, and Emotional Learning (CASEL). (n.d.). Fundamentals of SEL. https://casel.org/fundamentals-of$\underline{\text { sel/ }}$

Dawe, M. (2021, January 15). Same storm, different boats: COVID-19 and Indigenous communities. ALiGN: Alternative Global Network Media Lab. https://carleton.ca/align/2021/same-storm-different-boats-covid-19-and-indigenous-communities/

Dorado, J., Martinez, M., McArthur, L., \& Leibovitz, T. (2016). Healthy environments and response to trauma in schools (HEARTS): A whole-school, multi-level, prevention and intervention program for creating trauma-informed, safe and supportive schools. School Mental Health, 8, 163-176. http://dx.doi.org/10.1007/s12310-016-9177-0

Durlak, J. A., Weissberg, R. P., Dymnicki, A. B., Taylor, R. D., \& Schellinger, K. B. (2011). The impact of enhancing students' social and emotional learning: A meta-analysis of school-based universal interventions. Child Development, 82(1), 405-432. https://doi. org/10.1111/j.1467-8624.2010.01564.x

Felliti, V. J., Anda, R. F., Nordenberg, D., et al. (1998). Relationship of childhood abuse and household dysfunction to many of the leading causes of death in adults: The Adverse Childhood Experiences (ACE) Study. American Journal of Preventive Medicine, 14(4), 245-258. https://doi.org/10.1016/s0749-3797(98)00017-8

Friendly, M., Ballantyne, M., Anderson, L. (2020, July 30). Rebuilding childcare in Canada must include a national strategy. Policy Options. https://policyoptions.irpp.org/magazines/july-2020/rebuilding-childcare-in-canada-must-include-a-national-strategy/

Friendly, M., Forer, B., \& Vickerson, R. (2020, June 4). The pandemic experience has created an uncertain future for Canadian child care services: Highlights of a national survey. Report prepared for the Childcare Resource and Research Unit, Canadian Child Care Federation and Child Care Now. https://childcarecanada.org/

Government of Canada. (2021a). Budget 2021: Address by the deputy prime minister and minister of finance. https://www.canada.ca/en/ department-finance/news/2021/04/budget-2021-address-by-the-deputy-prime-minister-and-minister-of-finance.html

Government of Canada. (2021b). COVID-19 daily epidemiology update. https://health-infobase.canada.ca/covid-19/epidemiologicalsummary-covid-19-cases.html

Gray, D. (2007). Creating resilience after neglect and trauma. Perspectives Press.

Greenberg, M. T., Weissberg, R. P., Utne O’Brien, M., Zins, J. E., Fredericks, L. Resnik, H., et al. (2003). Enhancing school-based prevention 
and youth development through coordinated social, emotional, and academic learning. American Psychologist, 58, 466-474. https://psycnet.apa.org/doi/10.1037/0003-066X.58.6-7.466

Harper, D. J., \& Cromby, J. (2020). From "What's wrong with you?" to "What's happened to you?": An introduction to the special issue on the power threat meaning framework. Journal of Constructivist Psychology. https://doi.org/10.1080/10720537.2020.1773362

Hatton-Bowers, H., Howell Smith, M., Huynh, T., Bash, K., Durden, T., Anthony, C., \& Lodl, K. (2020). “I will be less judgmental, kinder, more aware, and resilient!": Early childhood professionals' learnings from an online mindfulness module. Early Childhood Education Journal, 48(3), 379-391. https://link.springer.com/article/10.1007\%2Fs10643-019-01007-6

Hodson, J., Hedican, N., Huston, L., Mason, B., Junnila, M., Falcigno, K., \& Evans, K. (2020). Indigenous ECE leadership professional development program (IECEPDP) Anishininiiwi awaashishiiw kihkinohamaakewi niikaanihtamaakew: A summative report. http://indigagogy.com

Jagers, R. J., Rivas-Drake, D., \& Williams, B. (2019). Transformative social and emotional learning (SEL): Toward SEL in service of educational equity and excellence. Educational Psychologist: Social and Emotional Learning, 54(3), 162-184. https://doi.org/10. $\underline{1080 / 00461520.2019 .1623032}$

Jennings, P. A., \& Greenberg, M. T. (2009). The prosocial classroom: Teacher social and emotional competence in relation to student and classroom outcomes. Review of Educational Research, 79(1), 491-525. https://doi.org/10.3102\%2F0034654308325693

Jones, S. M., \& Doolittle, E. J. (2017). Social and emotional learning: Introducing the issue. The Future of Children, 27(1), 3-11. https:// doi.org/10.1353/foc.2017.0000

Lawson Foundation. (2020, July). Increasing outdoor play in early learning and child care in the context of COVID-19. http://www.lawson. ca/op-elcc-covid19.pdf

Mashburn, A. J., \& Pianta, R. C. (2006). Social relationships and school readiness. Early Education and Development, 17, 151-176. https:// psycnet.apa.org/doi/10.1207/s15566935eed1701 7

Nicholson, J., Perez, L., \& Kurtz, J. (2018). Trauma-informed practices for early childhood educators: Relationship-based approaches that support healing and build resilience in young children. Routledge.

Oberle, E., Domitrovich, C. E., Meyers, D. C., \& Weissberg, R. P. (2016). Establishing systemic social and emotional learning approaches in schools: A framework for schoolwide implementation. Cambridge Journal of Education, 46(3), 277-297. https://doi.org/10.1 $\underline{080 / 0305764 X .2015 .1125450}$

Oberle, E., \& Schonert-Reichl, K. A. (2016). Stress contagion in the classroom? The link between classroom teacher burnout and morning cortisol in elementary school students. Social Science \& Medicine, 159, 30-37. https://doi.org/10.1016/j.socscimed.2016.04.031

Ohio Leadership Advisory Council. (n.d.). History of trauma-informed care and education. https://ohioleadership.org/

Razza, R. A., Linsner, R. U., Bergen-Cico, D., Carlson, E., \& Reid, S. (2019; 2020). The feasibility and effectiveness of mindful yoga for preschoolers exposed to high levels of trauma. Journal of Child and Family Studies, 29(1), 82-93. https://link.springer.com/ article/10.1007/s10826-019-01582-7

Read, J., \& Harper, D. J. (2020). The power threat meaning framework: Addressing adversity, challenging prejudice and stigma, and transforming services. Journal of Constructivist Psychology. https://doi.org/10.1080/10720537.2020.1773356

Record-Lemon, R. M., \& Buchanan, M. J. (2017). Trauma-informed practices in schools: A narrative literature review. Canadian Journal of Counselling and Psychotherapy, 51(4), 286-305. https://cjc-rcc.ucalgary.ca/article/view/61156/pdf

Sam, M. A. (2019). Contextualizing approaches to Indigenous peoples' experiences of intractable conflict. New England Journal of Public Policy, 31(1), Article 5. https://scholarworks.umb.edu/nejpp/vol31/iss1/5

Sherwood, D., VanDeusen, K, Weller, B., \& Gladden, J. (2021): Teaching note-Teaching trauma content online during COVID-19: A trauma-informed and culturally responsive pedagogy. Journal of Social Work Education, 57(sup1), 99-110. https://doi.org/10. $\underline{1080 / 10437797.2021 .1916665}$ 
Statistics Canada. (2020, October 20). COVID-19 in Canada: A six-month update on social and economic impacts. https://www150. statcan.gc.ca/n1/pub/11-631-x/11-631-x2020003-eng.htm

Substance Abuse and Mental Health Services Administration. (2014, July). SAMHSA's concept of trauma and guidance for a traumainformed approach. https://ncsacw.samhsa.gov/userfiles/files/SAMHSA Trauma.pdf

Sweifach, J., Linzer, N., \& LaPorte, H. H. (2012). A social worker's duty to care: The self-other dimension of disaster response. Traumatology, 19(1), 3-10. https://doi.org/10.1177/1534765612441977

Truth and Reconciliation Commission of Canada. (2015). Summary of the final report of the Truth and Reconciliation Commission of Canada. https://ehprnh2mwo3.exactdn.com/wp-content/uploads/2021/01/Executive Summary English Web.pdf

United Nations. (n.d.). COVID-19 and Indigenous peoples. https://www.un.org/

Warren, M. A., \& Bordoloi, S. D. (2020). When COVID-19 exacerbates inequities: The path forward for generating wellbeing. International Journal of Wellbeing, 10(3), 1-6. https://internationaljournalofwellbeing.org/index.php/ijow/article/view/1357/925

Whitington, V., \& McInnes, E. (2017). Developing a "classroom as community" approach to supporting young children's wellbeing. Australasian Journal of Early Childhood, 42(4), 2229. https://doi.org/10.23965\%2FAJEC.42.4.03

Yang, J., Allen, K., Mendleson, R., \& Bailey, A. (2020, July 11). Toronto's COVID-19 divide: The city's northwest corner has been "failed by the system." Toronto Star. https://www.thestar.com/news/gta/2020/06/28/torontos-covid-19-divide-the-citys-northwestcorner-has-been-failed-by-the-system.html

Yong, E. (2021, July 22). America is getting unvaccinated people all wrong. The Atlantic. https://www.theatlantic.com/health/ archive/2021/07/unvaccinated-different-anti-vax/619523/ 